\title{
ANÁLISE ESPACIAL NO SÍTIO ENGENHO DO MEIO: UMA ABORDAGEM COM BASE NA CARTOGRAFIA HISTÓRICA DO BAIRRO DA VÁRZEA, RECIFE-PE
}

iDiscente (Mestrado) do Programa de Pós-graduação em Arqueologia da Universidade Federal de Pernambuco - UFPE iiDiscente (Doutorado) do Programa de Pós-graduação em Arqueologia da Universidade Federal de Pernambuco - UFPE iiiDocente do Departamento de Arqueologia da Universidaded federal de Pernambuco - UFPE

\author{
Leandro Souza $^{i}$ \\ Lucas Bonaldii \\ José Nicodemos Chagasi \\ Daniele Liberato ${ }^{i i}$ \\ Camila Ferreira ${ }^{i}$ \\ Demétrio Mutzenbergiii
}

Resumo: Este trabalho teve por objetivo, georreferenciar dados cartográficos históricos da malha urbana do Recife, norteando os trabalhos de escavações realizadas no Sítio Arqueológico Histórico Engenho do Meio da Várzea, e comparar as estruturas evidenciadas em campo com as informações contidas nos mapas históricos da área. A abordagem metodológica utilizada, teve como base a utilização de mapas históricos do Bairro da Várzea, referentes aos séculos XIX e XX, e a localização de marcos que perduram na paisagem, tais como a Igreja Matriz da Várzea e o Cemitério da Várzea. Com o auxílio de pontos georreferenciados mediante a técnica de posicionamento Real Time Kinematic (RTK) e um Veículo Aéreo Não Tripulado (VANT), foram gerados Modelos Digitais de Elevação (MDE), Modelos Digitais de Terreno (MDT) e Ortomosaicos do sítio arqueológico e da área escavada, que serviram para comparar os dados atuais com os históricos através de uma sobreposição espacial. Pôde-se perceber que a estrutura evidenciada durante a escavação, coincide, nas convenções cartográficas existentes nos mapas do século XIX, ao que provavelmente se tratava do conjunto arquitetônico do Engenho do Meio. Palavras-Chaves: Arqueologia Histórica, Engenho do Meio, Georreferenciamento.

\begin{abstract}
This work which aimed to georeference historical cartographic data from the urban mesh of Recife, guiding the excavation work carried out at the Engenho do Meio da Várzea Historical Site and comparing the structures evidenced in the fieldwork within the information contained in the historical maps from the area. The methodological approach used in this research, was based on the use of historical maps from the 19th and 20th centuries of the Varzea neighborhood, and the location of landmarks that exist in the landscape, such as the Várzea Mother Church and Cemetery. With the aid of georeferenced points using a real-time kinematic (RTK) positioning technique and a low-cost Unmanned Aerial Vehicle (UAV), were created Digital Elevation Models (DEM), Digital Terrain Models (DTM) and Orthomosaics of the archaeological site and the excavated area, which serves to compare the current data with the historical data through a spatial overlap. It was possible to notice that the structure evidenced during the archaeological excavation, coincides with the cartographic conventions existing in the maps of the 19th century, which certainly was the architectural ensemble of the Engenho do Meio. Keywords: Historical Archaeology, Engenho do Meio, georeferencing.
\end{abstract}




\section{Introdução}

Este trabalho é o resultado da disciplina Sistema de Informação Geográfica que teve como propósito georreferenciar dados cartográficos históricos da malha urbana do Recife, com recorte na área que circunscreve o sítio arqueológico histórico Engenho do Meio da Várzea. Trata-se de um sítio arqueológico histórico que está localizado dentro do Campus da Universidade Federal de Pernambuco (UFPE), no bairro da Cidade Universitária, Recife-PE (Figura 1).

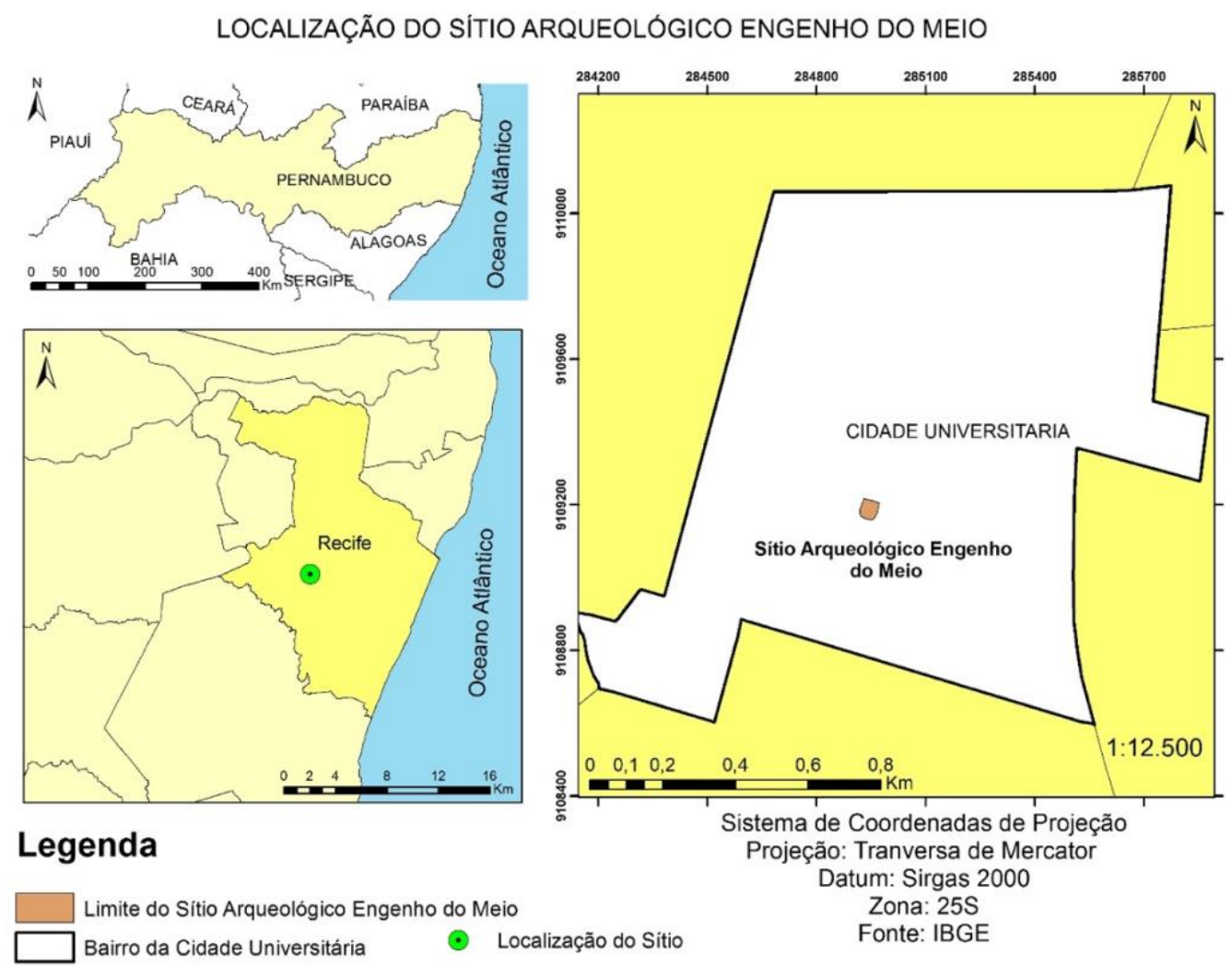

Figura 1: Mapa político de localização do Sítio Arqueológico Engenho do Meio

O propósito da disciplina foi nortear os trabalhos de escavações realizadas e comparar as estruturas evidenciadas com as informações contidas nos mapas históricos para a área, buscando uma ligação com as convenções cartográficas desses mapas de modo a somar no entendimento do registro arqueológico do sítio. O contexto no qual o sítio se insere corresponde ao século XVII, onde os Engenhos eram os principais veículos de produção da Cana de Açúcar, na Sesmaria de Pernambuco (Almeida \& Lisboa, 2014; Jr. Silva, 2017). 


\section{As Interfaces da Arqueologia}

A utilização das tecnologias computacionais não é novidade no cenário arqueológico, porém com o avanço computacional a gama de possibilidades informáticas aplicadas às humanidades, de uma forma geral, cresceu, e demanda uma especialização e um contato ainda maior com as Ciências da Informação.

Abarcando todas essas "novas" possibilidades dentro da Arqueologia, surge o termo "Arqueologia Digital", conceituado como a capacidade de diferentes técnicas e/ou tecnologias de serem aplicadas às diversas etapas dos trabalhos arqueológicos (Torres, 2017). O termo aparece na literatura pela primeira vez em 1988, mas seu uso só é impulsionado em 2003 pelo avanço computacional ocorrido no início do século XXI (Hugget, 2012).

Sob uma perspectiva mais específica, a Arqueologia Digital pode ser dividida em duas vertentes: Arqueologia Virtual e a Cyber-Arqueologia; sendo a primeira voltada para estudos que envolvem um sistema de dados estáticos e não modificáveis, e a segunda trabalha com dados dinâmicos, capazes de gerar ambientes virtuais que simulam a realidade, em outras palavras, pode-se pondera que em uma são feitas reconstruções do passado e na outra simulações, respectivamente (Olivito, Taccola \& Albertini, 2016).

Dentro do ramo da Arqueologia Virtual, destacam-se o uso do Sistema de Informação Geográfica (SIG), ferramenta já consolidada na Arqueologia com diversas aplicações e que auxiliam várias funções no contexto arqueológico, sendo a cartografia histórica e a gestão de modelos digitais de terreno, algumas dessas possibilidades oferecidas pelos SIG (Souza, 2014; Torres, 2017).

A análise da cartografia histórica torna-se fundamental para se compreender as mudanças ocorridas no cenário urbano e rural, ajudando a perceber a evolução da paisagem entorno do objeto de estudo, além do mais, auxilia na busca por estruturas de locais remanescentes de ocupações passadas.

As recorrências físicas, tais como, edificações ou qualquer tipo de marco paisagístico, presentes nos produtos cartográficos dos diversos períodos estudados, servem como referência para deixar os produtos localizados geograficamente, permitindo uma análise sobreposta e comparativa dos mapas (Castro, 2014). 
Outra técnica que vem ganhando espaço na Arqueologia é a fotogrametria, presente mais no campo da Cyber-Arqueologia, e suas diversas derivações como a aerofotogrametria e a fotogrametria a curta distância (Tommaselli et al., 1999; Pessis et al., 2014). Segundo Cabrelles et al (2017), esta é uma ciência capaz de realizar medições e reconstruções de modelos em segunda e terceira dimensão, de qualquer objeto, a partir de imagens em diferentes ângulos e escalas.

No que diz respeito a parte prática, a Arqueologia pode se aproveitar da fotogrametria para realizar prospecções seja com a utilização de câmeras comuns (Carvalho, 2002), ou até câmeras térmicas (Casana et al 2017). Outra utilização prática da fotogrametria, é no auxílio a topografia arqueológica (Abadía, 1998; Fonstad et al, 2013; Gutierrez et al, 2016; Thomas \& Kennedy, 2016; Thomas, 2017) ou no auxílio ou na substituição dos desenhos ou registros da escavação arqueológica (De Reu, 2014; Douglas, Lin e Chodoronek, 2015; Thomas, 2017), pois ela permite criar representações tridimensionais em escala, de qualquer sítio ou escavação arqueológica.

A fotogrametria também pode ser usada na preservação do patrimônio cultural, pois a partir de seus produtos é possível expor os dados de uma forma muito mais interativa com o público em geral, nesse quesito já há inúmeros trabalhos focados nas questões de difusão do conhecimento arqueológico através de ferramentas como os jogos virtuais, a impressão $3 d$, a realidade virtual e a realidade aumentada (Pessis et al., 2014; Lozano et al, 2015; Caro e Hansen, 2015; Jorayev et al, 2016; Valero e Huete, 2016, Champion, 2017; Fleming e Mortaio, 2017).

Considerando essas questões, o presente trabalho teve como abordagem a utilização da Fotogrametria no monitoramento vertical da escavação, ou seja, auxiliando na topografia e gerando produtos mais detalhados e simples de serem compartilhados e analisados.

Segundo observou Gutiérrez et al. (2016), em um estudo comparativo entre a topografia tradicional e a fotogrametria como auxiliar da primeira, realizado em uma área controlada, percebeu-se, que a segunda tem resultados superiores a primeira em alguns aspectos, como elencados na tabela abaixo (Tabela 1 ). 
Tabela 1. Comparação no uso da Estação Total e na Fotogrametria com VANTs

\begin{tabular}{|l|l|}
\multicolumn{1}{|c|}{ Prós - Estação Total } & \multicolumn{1}{c|}{ Prós - Fotogrametria com VANTs } \\
\hline Testado & Barato (modelos de baixo custo) \\
\hline Acurácia & Flexível \\
\hline Confiável & Fácil de aprender \\
\hline Durável & Fácil de operar \\
\hline Fácil Processamento dos dados & Rápida obtenção de dados em campo \\
\hline Trabalha em qualquer ambiente & Gera muitos produtos \\
\hline \multicolumn{1}{|c|}{ Contras - Estação Total } & Contras - Fotogrametria com VANTs \\
\hline Alto custo & Resultados pobres em vegetações densas \\
\hline Mais difícil de aprender & Sistema complexo propenso a falhas \\
\hline Dificuldades para operar & Acurácia depende de Pontos de Controle \\
\hline Consome tempo em campo & $\begin{array}{l}\text { Processamento de dados, a depender da máquina, pode durar } \\
\text { muito tempo }\end{array}$ \\
\hline Gera poucos produtos & Risco de quebras durante o voo \\
\hline & Custos com reparos eletrônicos \\
\hline & Alto custo para investir em modelos mais avançados \\
\hline
\end{tabular}

\section{Considerações Históricas da Área De Estudo}

O terreno onde o Campus da Universidade Federal de Pernambuco (UFPE) foi implantado, no atual bairro da Cidade Universitária, foi sede de uma pequena povoação do século XVI, originária do Engenho Santo Antônio, fundado nos primeiros anos da colonização por Diego Gonçalves. Em detrimento da fertilidade dos solos dessa área, à época foi escolhida para o plantio de cana-de-açúcar. Essas terras foram as primeiras a serem repartidas entre os colonos portugueses que iniciaram a povoação de Pernambuco, por volta da primeira metade do século XVI (Almeida \& Lisboa, 2014; Jr. Silva, 2017).

O primeiro engenho do lugar foi o Santo Antônio fundado nos primeiros anos da colonização por Diego Gonçalves, e o que ficaria mais conhecido foi o Engenho São João; foi edificada uma igreja matriz, dedicada à Nossa Senhora do Rosário. Essa igreja, presente na convenção cartográfica da Carta de 1875, foi um dos pontos que serviu para georreferenciar o mapa e fazer as comunicações neste trabalho. No entorno desta Igreja, cresceu a primeira freguesia suburbana do atual município do Recife, conforme assinala o Livro que dá razão do Estado do Brasil (1612). 
Conforme pontua Almeida \& Lisboa (2014) é nesse contexto histórico que é erguido o Engenho do Meio e a Casa Grande situada na margem direita do Rio Capibaribe, freguesia da Várzea, jurisdição de Olinda e capitania de Pernambuco, com moenda movida a bois. Dada essa característica, esse modelo de Engenho era conhecido como Banguês. Nesse momento os Engenhos eram os principais veículos de produção da Cana de Açúcar na Sesmaria de Pernambuco (Rodrigues \& Garcia, 2015).

O primeiro proprietário documentado do Engenho do Meio foi Álvaro Velho Barreto. Em 1609 o engenho do Meio pertencia à viúva de Álvaro, D. Luisa Nunes e filhos. Em 1625, D. Luiza declarou que estava impossibilitada de pagar aos seus credores e vendeu o engenho a Carlos Francisco Drago, que faleceu antes da invasão holandesa, ficando o engenho nas mãos de seus herdeiros. Em 1637 o engenho é confiscado pela Companhia das Índias Ocidentais e vendido a Jacob Stachouwer, alto funcionário do governo holandês no Recife. Após a partida de Stachower para a Holanda o engenho ficou sob os cuidados de seu amigo e feitor, o Procurador João Fernandes Vieira (Francisco de Ornelas Moniz Júnior) e D. Maria César (Almeida \& Lisboa, 2014; Jr. Silva, 2017; Silva, 2009).

Em 1686, D. Maria César, então viúva de João Fernandes Vieira, herdou as terras do Engenho. No início do século XVIII, o Engenho passou às posses de João Carneiro da Cunha, que ao falecer transferiu a propriedade ao seu filho, José Carneiro da Cunha (1680-1757). Conforme pontua Silva (2009), entre 1900 e 1905, no local foi instalada uma usina e, a estrutura da Casa Grande do Engenho resistiu até a década de 1940. A partir do século XX, essas terras, que surgiram de uma povoação em torno do antigo engenho, foram reocupadas, dando início a uma nova configuração geográfica da área.

Em 1948 com a implantação da Universidade Federal de Pernambuco, a Casa Grande foi demolida, restando apenas as ruínas. No local há uma estátua em homenagem à João Fernandes Vieira, que, conforme supracitado, foi um dos proprietários ao longo da existência histórica do Engenho.

\section{O Sítio Arqueológico Histórico Engenho do Meio}

O sítio é representado por remanescentes arqueológicos históricos como faianças, cerâmicas e pelas estruturas da antiga Casa grande do Engenho do Meio. As primeiras escavações no local 
foram iniciadas em 1997, através de abertura de trincheiras para que fosse verificado o contexto de subsuperfície do sítio, entretanto, a escavação durou pouco tempo.

Em 2018, as escavações no sítio foram retomadas e o local foi transformado em sítio escola, sendo usado para ensinar os métodos e técnicas de escavação arqueológica para alunos da graduação e pós-graduação do Departamento de Arqueologia da Universidade Federal de Pernambuco (UFPE).

A partir dessas questões, a equipe do presente trabalho, quando da realização dos procedimentos de campo, ponderou alguns pontos discutidos nas literaturas históricas, que correspondem a: escolha do local como ponto estratégico da ocupação que, conforme discute Silva (2017), de modo a interligar o interior (a Várzea) à cidade (Recife Antigo) criaram "O caminho colonial da Várzea" que tinha como jusante o Riacho do Cavouco. Outra questão corresponde a escolha dos espaços (relevo) para construção das casas e engenhos, ou seja, na ausência de um espaço com topografia elevada, soerguiam as casas para evitar as enchentes, e estas, por sua vez, entram como uma variável porque favorecia à fertilização dos solos. Essas são algumas das características que, na realização de um estudo com emprego de técnicas análise espacial, devem ser consideradas porque conseguem nortear o trabalho.

\section{Abordagem Metodológica}

As atividades em campo foram realizadas por uma equipe composta de alunos, tanto do mestrado como do doutorado em Arqueologia da UFPE, inscritos na disciplina, sob coordenação do Prof. Dr. Demétrio Mutzenberg. Tais procedimentos consistiram no levantamento topográfico da área do sítio concomitante às escavações que eram realizadas pelos alunos de Graduação em Arqueologia, coordenados pelo Prof. Dr. Scott Allen.

Dentro do perímetro do sítio foram marcados, anteriormente, pontos georreferenciados mediante a técnica de posicionamento Real Time Kinematic (RTK) para servir de base georreferenciada ao levantamento topográfico e fotogramétrico. Uma vez identificados os pontos, houve a delimitação da malha da escavação de 2018.

Objetivando ter uma dimensão da área em sua completude, foi utilizado um Veículo Aéreo Não Tripulado (VANT) de baixo custo (DJI Mavic Pro) para realizar um levantamento aerofotogramétrico do sítio arqueológico e das áreas escavadas. Para a definição do plano de 
voo com o VANT, foi utilizada a plataforma Dronedeploy. Os dados obtidos a partir dos voos de drone, foram tratados no software Agisoft PhotoScan Professional para geração dos Modelos Digitais de Elevação (MDE), Modelos Digitais de Terreno (MDT) e Ortomosaicos do sítio arqueológico e da área escavada. Os dados obtidos com o levantamento topográfico foram tratados no ArcMAP 10.4 e Auto CAD 2018 a fim de gerar uma base de mapas

O levantamento topográfico foi realizado com a estação total Leica TSO2, buscando multiplicar pontos de controle no terreno. Os voos com o VANT foram realizados com altitudes diferentes, um de maior detalhe, voando bem próximo ao solo, a cerca de $10 \mathrm{~m}$ da área escavada e um outro a cerca de $60 \mathrm{~m}$, a fim de evidenciar o contexto do sítio. Os dados topográficos foram fundamentais para gerar um modelo digital do perímetro do sítio, demostrando que o local onde foram evidenciadas estruturas se encontra em um setor mais elevado do sítio histórico.

Concomitante a esses procedimentos, procurou-se fazer um levantamento cartográfico de mapas ou dados cartográficos que mostrassem a evolução do bairro da Várzea. Durante essa etapa identificou-se documentos que detinham informações que a equipe julgou ser importante ao viés do trabalho: uma carta histórica de 1875, outra de 1945 e uma terceira mais recente, contendo dados contemporâneo e georreferenciados, onde havia as principais vias e os limites da cidade do Recife (Figura 2).

Com estes dados reunidos, foram observadas áreas recorrentes nos três mapas e que pudessem ser usadas para realizar uma triangulação, a fim de georreferenciar os mapas antigos. A Igreja Matriz da Várzea e o Cemitério da Várzea, surgem como elementos que perduraram ao longo do tempo e, portanto, auxiliaram nesse posicionamento. Algumas esquinas ou marcos cartográficos também foram usados para refinar o georreferenciamento, como é o caso do curso do Riacho do Cavouco, que tem sua nascente dentro do atual terreno da UFPE. 


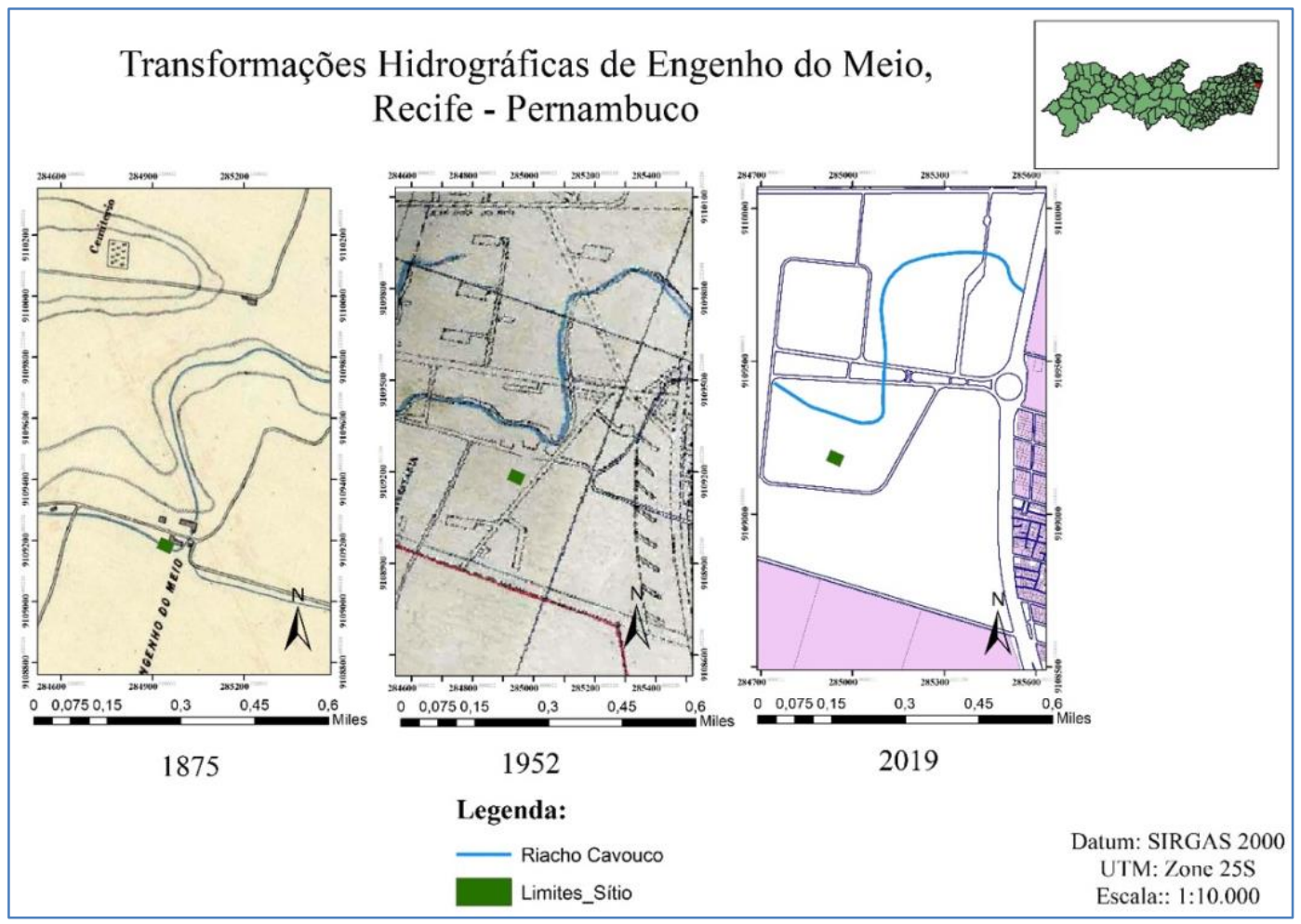

Figura 2. Mapa com as transformações na rede hidrográfica do Riacho do Cavouco.

\section{Resultados}

No setor escavado foi evidenciada parte de uma possível estrutura. Esta, conforme convenções cartográficas existentes nos mapas do século XVII e XIX, apontam ser um resquício do conjunto arquitetônico da Casa grande do Engenho do Meio. A elevação do terreno, no setor escavado corrobora com as hipóteses da escolha do espaço para construir a casa conforme discutido acima.

Observa-se algumas questões importantes. As duas convenções que atestam a localização do Cemitério e a Igreja Matriz da Várzea, já estão presentes na carta de 1875 (Figura 3). 0 traçado do riacho do Cavouco serpenteia a área onde o engenho está situado. O caminho colonial da várzea está tracejado em tom mais escuro que adentra ao meio o quadrante que demonstra a Casa grande. A sobreposição dos dados atuais na carta mostra, sobretudo, o curso do riacho, que à época poderia ter existido mais distante da casa ou ter sido desviado. 


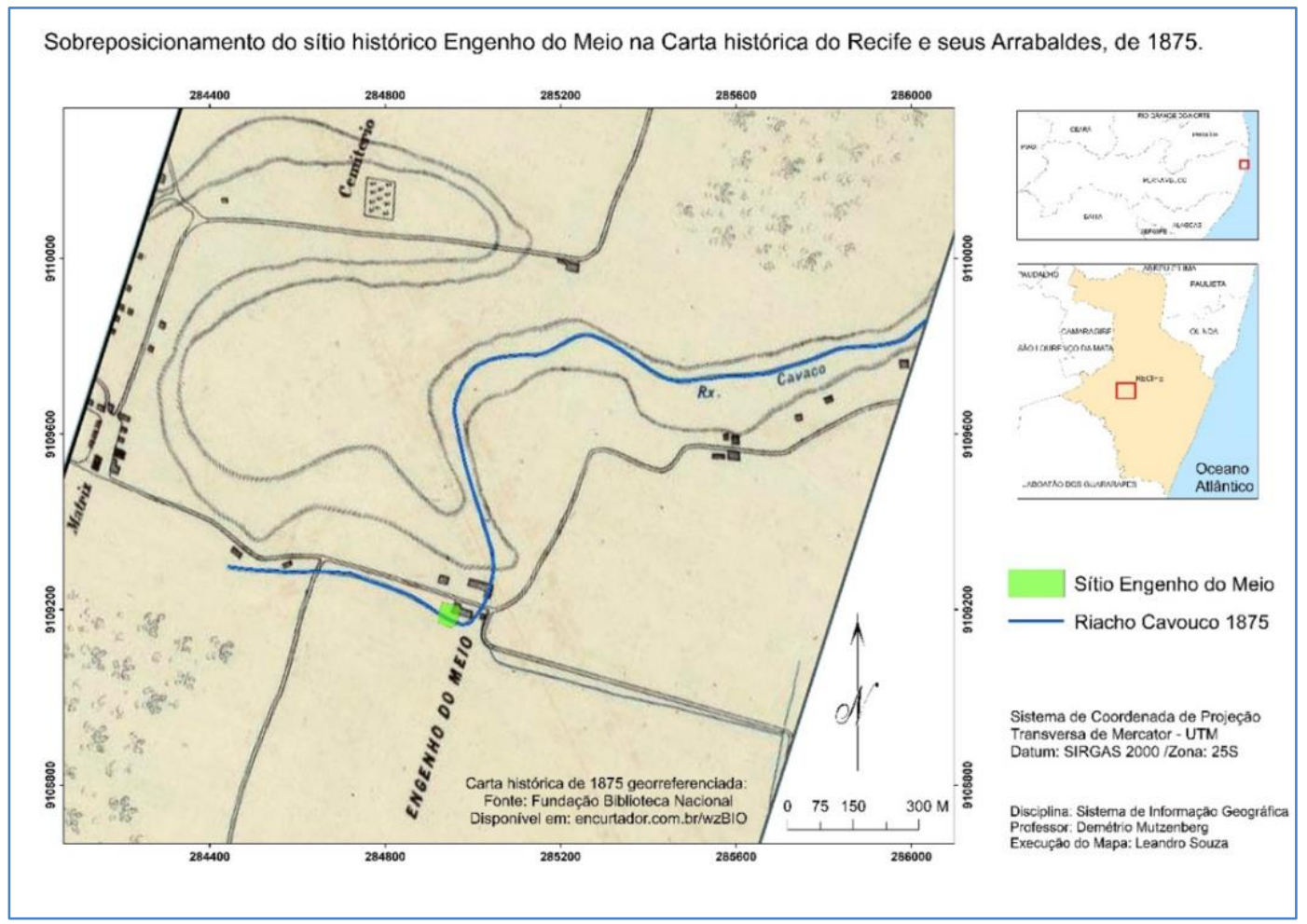

Figura 3. Carta histórica de 1875 georreferenciada - Fonte: Fundação da Biblioteca Nacional.

Na carta georreferenciada de 1956 (Figura 4), observa-se que o traçado urbano na área é maior, já apresentando os limites da Universidade Federal de Pernambuco. A sobreposição do riacho na carta já coincide com os dados atuais. Na Figura 3, levantou-se a possibilidade de o riacho ter sido deslocado, ou apenas havido divergências nas escalas. Um detalhe importante é que o local onde há o caminho colonial da várzea, à época, está atualmente como uma via que interliga o local ao atual bairro do Engenho do Meio. Foram então sobrepostos os dados atuais da malha urbana do Recife de modo a ter uma compreensão a respeito crescimento do bairro (Figura 5).

Após apresentação das cartas históricas, faz-se agora essa apresentação com base nos dados produzidos pela equipe em campo. Na Figura 6, o primeiro frame apresenta o setor onde foi realizado a escavação que coincide com o possível local onde fora construída a Casa Grande. A imagem histórica na parte superior esquerda corresponde a Casa Grande, tirada antes de ser demolida. 


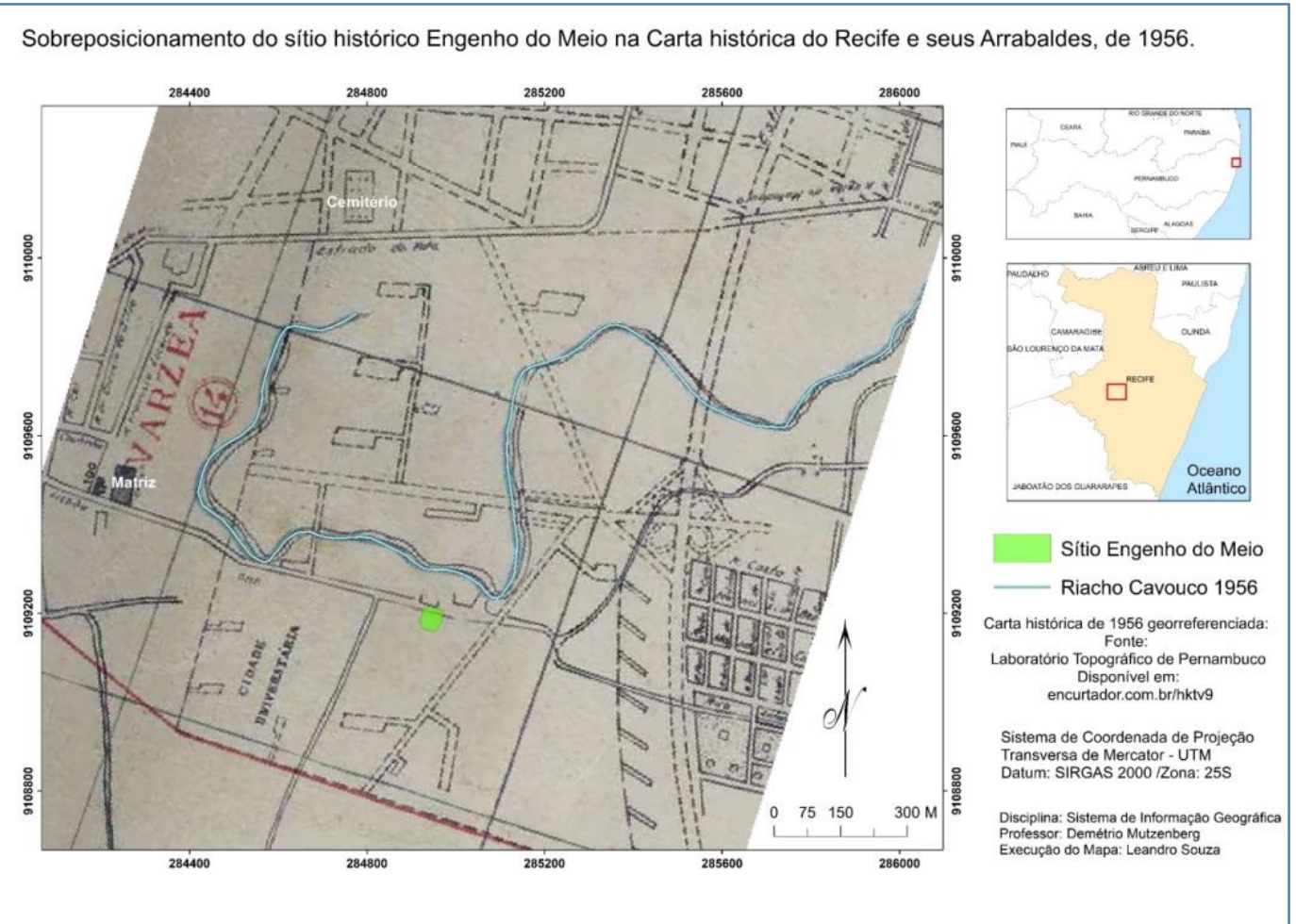

Figura 4: Sobreposicionamento do sítio histórico de Engenho do Meio na Carta Histórica do Recife e seus Arrabaldes, 1956.

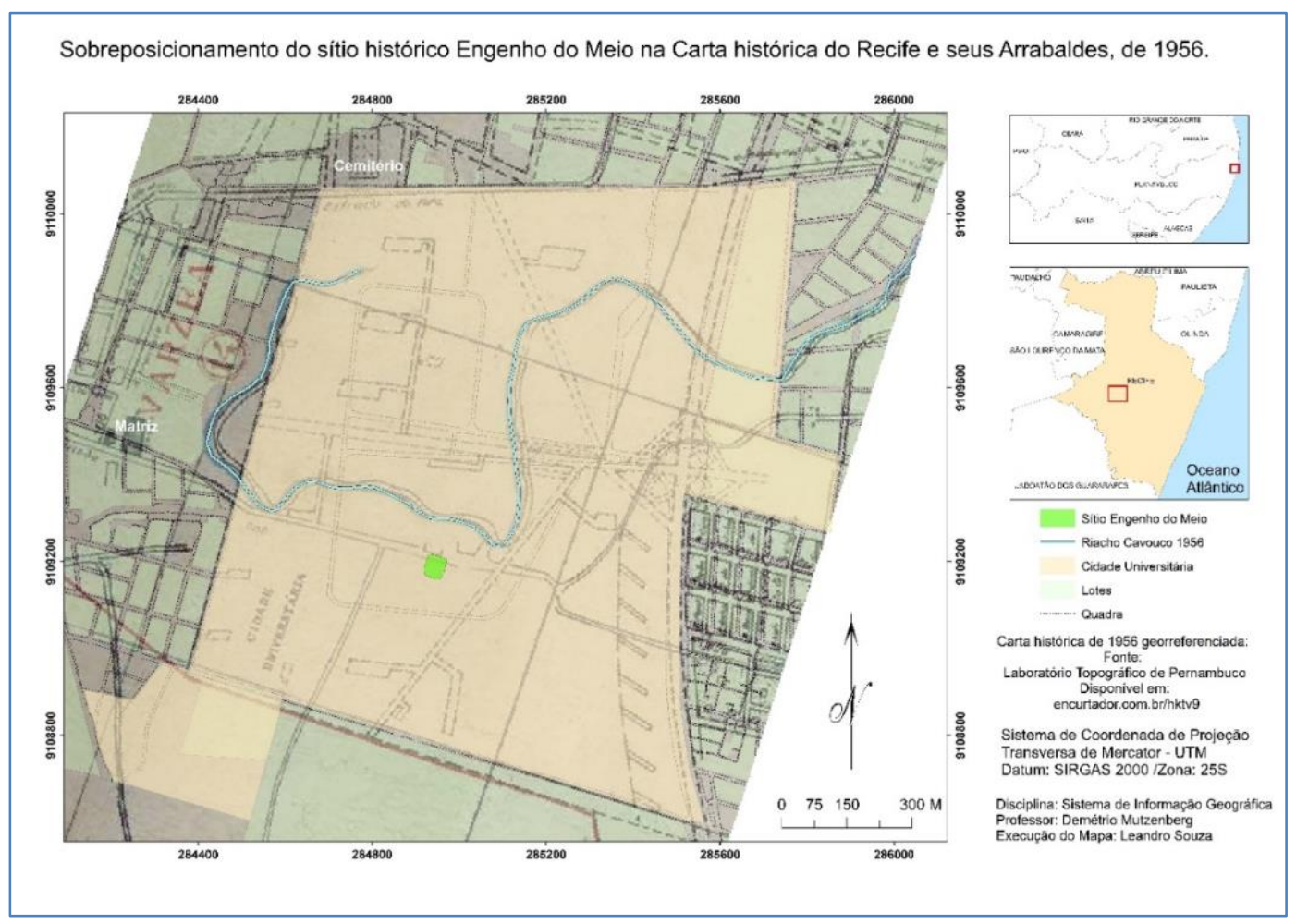

Figura 5: Sobreposicionamento do sítio histórico de Engenho do Meio na Carta Histórica do Recife e seus Arrabaldes, 1956 


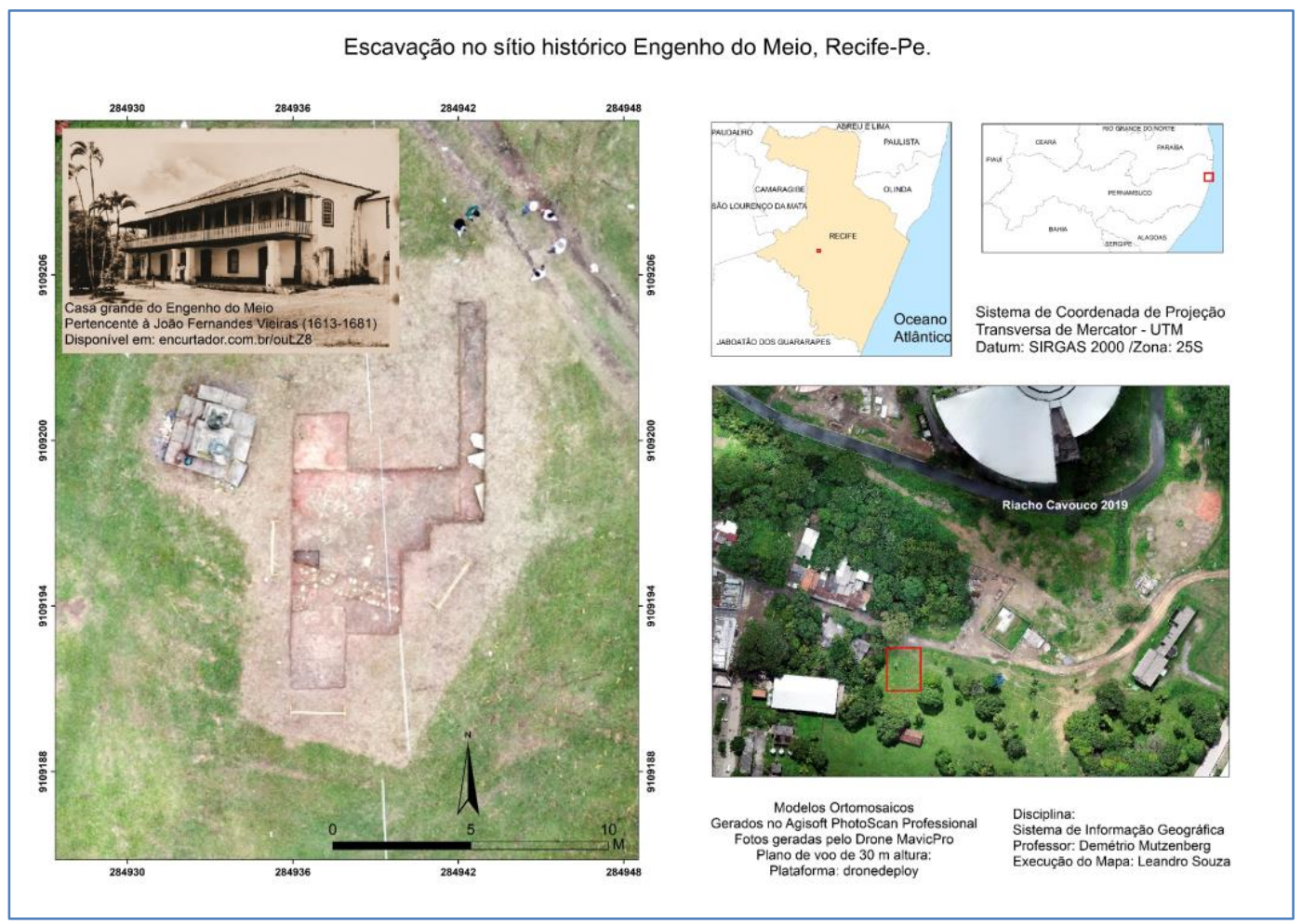

Figura 6. Escavação no sítio histórico de Engenho do Meio, Recife-PE.

A Figura 7, verifica-se a área já escavada como malha sobreposta e o limite do sítio definido com base no levantamento topográfico. Já na Figura 8, temos a representação hipsométrica da área do sítio confeccionado a partir do levantamento topográfico, sendo apresentado, à direita, o levantamento a partir dos voos de drone.

Sobre o processo de identificação da área escavada em 1997, a equipe utilizou um croqui da escavação antiga, através do uso do SIG e a marcação de pontos identificados na carta, como vegetação e a estátua, os pontos de malha da escavação foram plotados com a estação total e, em seguida, inserido a base de dados do SIG. Neste sentido, este levantamento auxiliou a equipe de escavação atual a respeito da estratégia utilizada na escavação atual. 


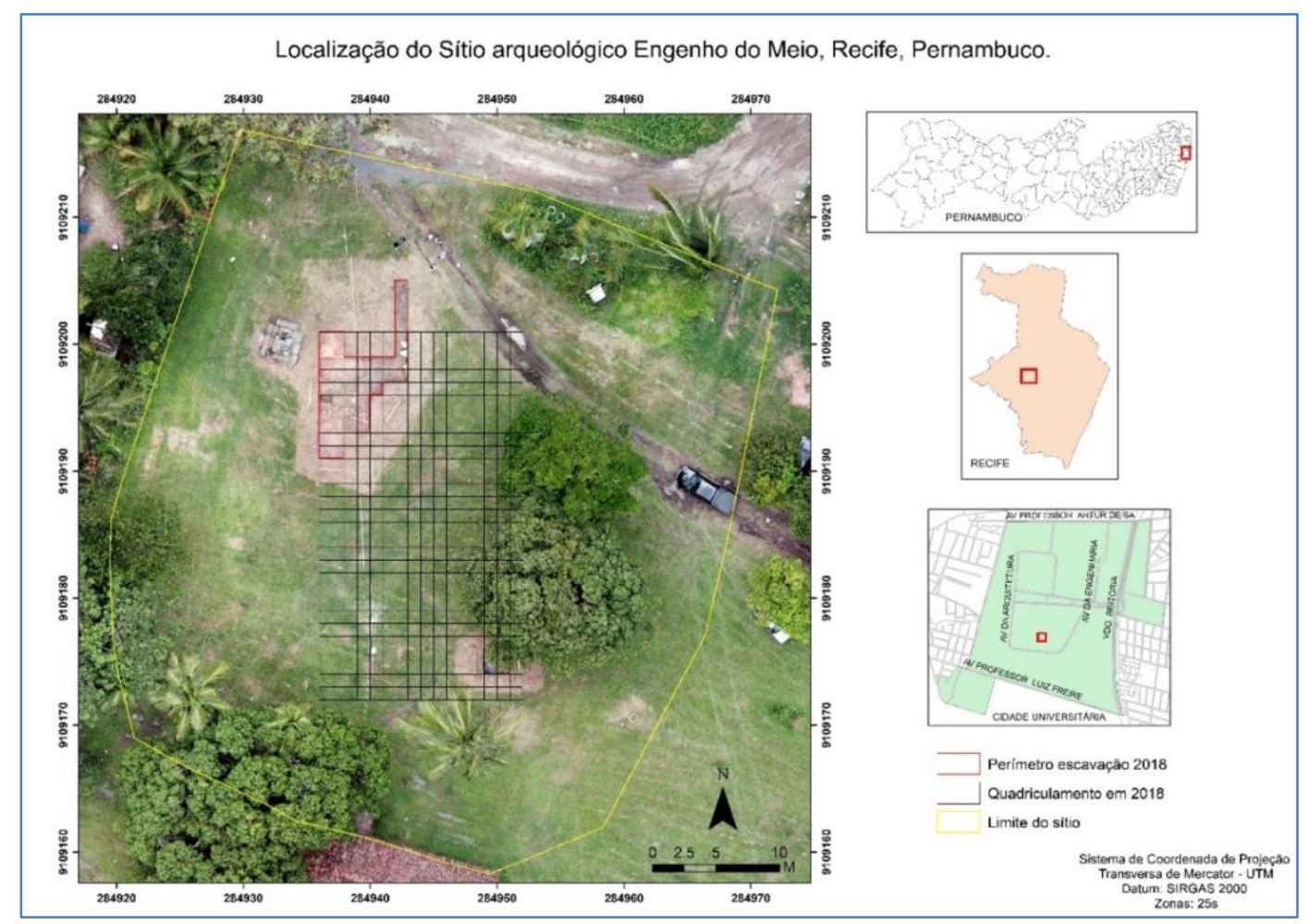

Figura 7: Apresentação da área da escavação com a malha delimitada

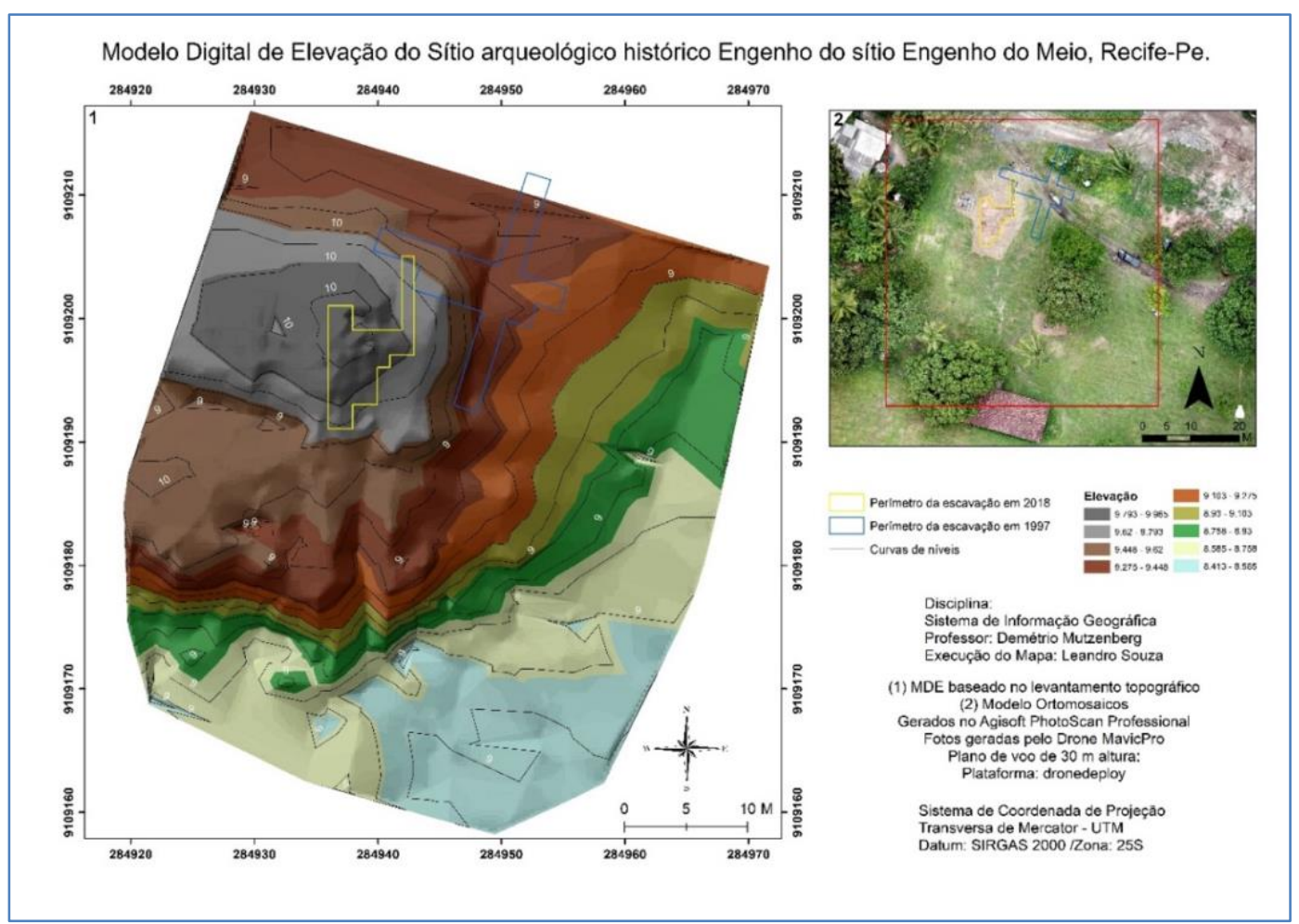

Figura 8: Representação hipsométrica da área do sítio confeccionado a partir do levantamento topográfico (frame a esquerda) e voos de drone (frame a direita) 
Na Figura 9, temos a apresentação do setor escavado, o mapa foi realizado através de conjuntos de imagens tiradas com drone em voos de $10 \mathrm{~m}$ de altura. Observa-se partes remanescentes de estruturas que, com base nas discussões históricas supracitadas, indicam possivelmente se tratar da Casa Grande do Engenho do Meio da Várzea.

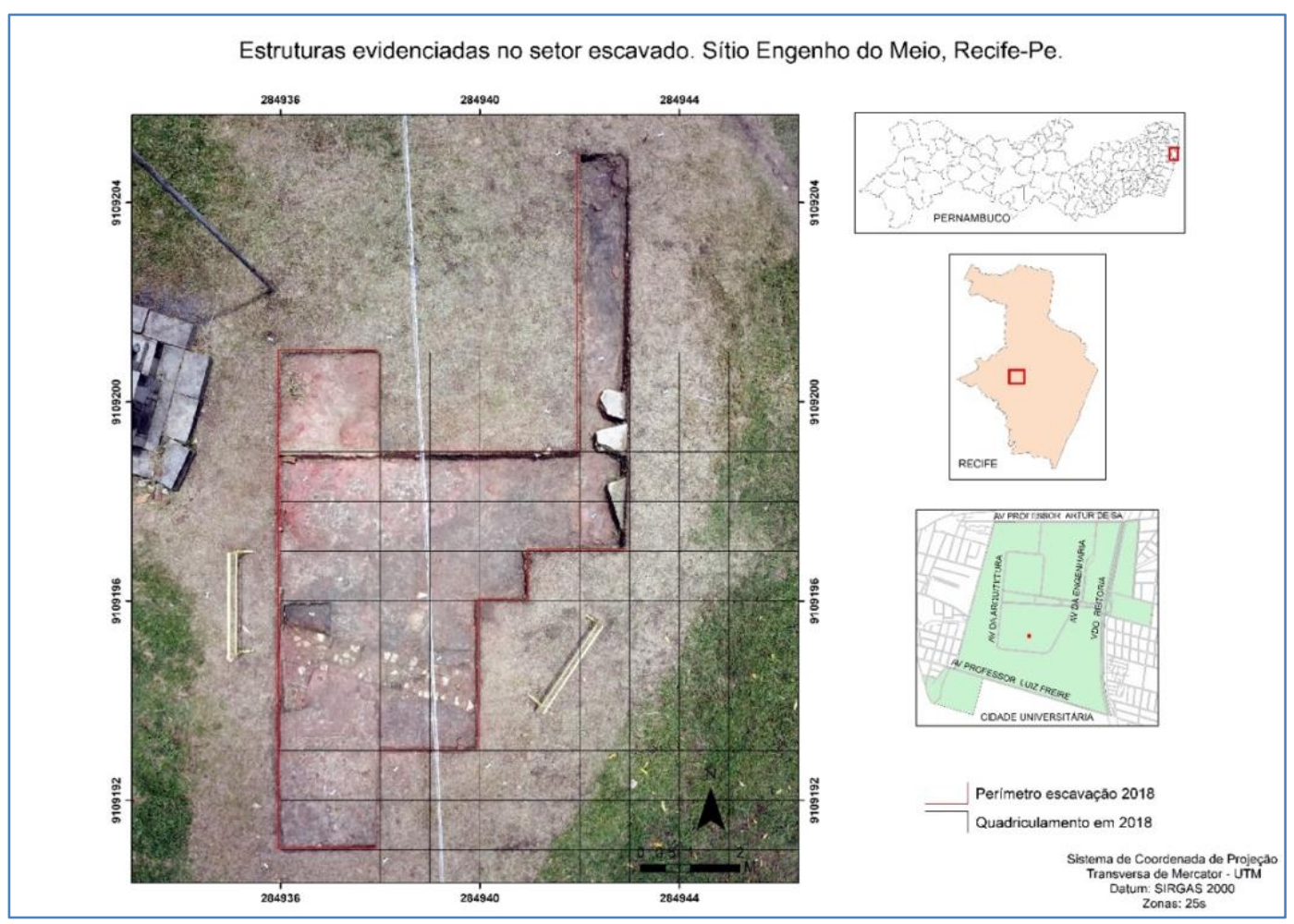

Figura 9: Área da escavação com a malha delimitada.

\section{Considerações Finais}

O presente trabalhou atuou no levantamento de dados de área de sítio arqueológico histórico, localizado em Campus da Universidade Federal de Pernambuco (UFPE), no bairro da Cidade Universitária, Recife-PE. O trabalho foi desenvolvido por equipe composta por mestrandos e doutorandos do Departamento de Arqueologia da citada Universidade, coordenados pelo Prof. Dr. Demétrio Mutzenberg.

Para este fim, a equipe atuou no sentido de criar modelos tridimensionais da área, como um modelo digital de terreno e um ortomosaico, utilizando um VANT de baixo custo (DJI Mavic Pro) e processando informações a partir de softwares como ArCMAP 2010, Auto CAD 2018 (versão estudante) e Agisoft PhotoScan Professional, além do uso do dronedeploy, que auxiliou no direcionamento no registro aerofotogramétrico. 
O resultado foi a produção de uma série de mapas, utilizando o Sistema de Informação Geográfica, que relacionou o levantamento histórico da área, os registros de escavação antigos e o atual trabalho de escavação do sítio arqueológico. A tecnológica aplicada permitiu a equipe obter informações que puderam acrescentar elementos estruturais, topográficos e georreferenciados para o desenvolvimento de atual trabalho de escavação, permitindo maior compreensão sobre o registro arqueológico do sítio.

As utilizações dos dados fotogramétricos foram importantes para avaliar o controle vertical da escavação, que, somado aos dados topográficos, forneceram uma melhor acurácia do terreno, possibilitando a observação de elementos que, eventualmente, não são observados em campo.

\section{Referências}

ABADÍA, M. F. et al. 1998. Topografía y cartografía arqueológica aplicada a reconstrucciones históricas en el Emirato de Sharjah (U.A.E.). Revista sobre Oriente Próximo y Egipto en la antigüedad, Madrid, v. 1, p. 288-296.

ALMEIDA, B.; LISBOA, V. 2014. Engenhos, açúcares e negócios na Capitania de Pernambuco (c. 1655 - c. 1750). Clio revista de pesquisa histórica v. 32, p. 1-19.

CABRELLES, M. et al 2017. From Multispectral 3D Recording and Documentation to Development of Mobile Apps for Dissemination of Cultural Heritage. In: LEVY, T. E.; JONES, I. W. N. Cyber-Archaeology and Grand Narratives: Digital Technology and Deep-Time Perspectives on Culture Change in the Middle East. Cham: Springer International Publisher.

CANUTO, M. A. et al 2018. Ancient lowland Maya complexity asrevealed by airborne laser scanning of northern Guatemala. Science, v. 361, p. 1-17.

CARNEIRO, G.F. 2018. As ruínas invisíveis do Engenho do Meio: uma proposta de Educação patrimonial na comunidade do Arruado da UFPE. Monografia (Bacharelado em Arqueologia), Universidade Federal de Pernambuco, Recife.

CARVALHO, A 2002. A Fotografia Aérea na Arqueologia. Ângulo, Tomar, v. 1, n. 1, p. 57-67.

CASANA, J. et al 2017. Archaeological Aerial Thermography in Theory and Practice. Advances in Archaeological Practice, Cambridge, p. 1-18.

CASTRO, J.F.M. 2014. Cartografia Histórica e Geoprocessamento: o exemplo dos mapas dos padres matemáticos, de 1734, e do cálculo de rendimentos gerais do Bispado de Mariana, de 1752. Revista do Departamento de Geografia - USP, v. Especial CARTOGEO, p. 123-140.

CHAMPION, E. 2017. Bringing your A-Game to Digital Archaeology: issues with serious games and virtual heritage and what we can do about it. The SAA Archaeological Record, v. 17, n.2, p. 24-27.

DE REU, J. et al. 2014. On introducing an image-based 3D reconstruction method in archaeological excavation practice. Journal of Archaeological Science, v. 41, p. 251-262. 
DOUGLASS, M.; LIN, S.; CHODORONEK, M. 2015. The Application of 3D Photogrammetry for InField Documentation of Archaeological Features. Advances in Archaeological Practice, Cambridge, v. 3, n. 2, p. 136-162

DOWLING, T. I.; READ, A. M.; GALLANT, J. C. 2009. Very high resolution DEM acquisition at low cost using a digital camera and free software. 18th World IMACS / MODSIM Congress. Cairns: [s.n.], p. 2479-2485.

FLEMING, M.I.D.; GREGORI, A.M. 2017. Ciberarqueologia e Aprendizagem: Os Aplicativos Digitais do LARP no Diálogo Entre Universidade e Ensino Básico. Revista de Cultura e Extensão da USP, v. 17, p. 6981.

FONSTAD, M. A. et al. 2013. Topographic structure from motion: a new development in photogrammetric measurement. Earth Surface Processes and Landforms, v. 38, p. 421-430.

GUTIÉRREZ, G. et al. 2016. Topography with small Unmanned Aerial Vehicles. The SAA Archaeological Record, v. 16, n. 2.

HUGGETT, J. 2012. Core or periphery? Digital Humanities from an archaeological perspective. Historische Sozialfoschung, v. 37, n. 3, p. 86-105.

IBGE, 2013. Censo Demografico 2010: Aglomerados Subnormais. [S.I: s.n.], 251 p. .9788524041884.

JORAYEV, G. et al. 2016. Imaging and photogrammetry models of Olduvai Gorge (Tanzania) by Unmanned Aerial Vehicles: A high-resolution digital database for research and conservation of Early Stone Age sites. Journal of Archaeological Science, v. 75, p. 40-56.

SILVA JUNIOR, L.S.da. 2017. O Caminho da Várzea do Capibaribe: O Engenho do Meio e sua Paisagem Arqueológica, Recife-PE. Arqueologia de Engenhos. [S.I: s.n.], p. 156-188.

LOZANO, J.F.; ALONSO, G.G. 2016. Improving archaeological prospection using localized UAVs assisted photogrammetry: An example from the Roman Gold District of the Eria River Valley (NW Spain). Journal of Archaeological Science: Reports, v.5, p. 509-520.

OLIVITO, R.; TACCOLA, E.; ALBERTINI, N. 2016. Cultural Heritage and Digital Technologies: Theory, Methods and Tools for the Study and Dissemination of Knowledge in the Archaeological Practice. In: FORTE, M.; CAPMANA, S. Digital Methods and Remote Sensing in Archaeology. Cham: Springer International Publisher, p. 475-494.

PESSIS, A.M.; CISNEIROS, D. MUTZENBERG, D. MEDEIROS, E. 2014. Modelos tridimensionais na análise de pinturas rupestres. In: Pessis, A.M. ; Martin, G.; Guidon, N. (Orgs.) Os Biomas e as Sociedades Humanas na Pré-História da Região do Parque Nacional Serra da Capivara, Brasil. São Raimundo Nonato, $A \& A$

RODRIGUES., M. 2015. História e cultura dos engenhos dentro da Cidade do Recife nas proximidades do Rio Capibaribe. Seta v. Ed. Especial.

SILVA, L.D. 2019. Várzea (bairro, Recife). Pesquisa Escolar Online, Fundação Joaquim Nabuco. Disponível em: <encurtador.com.br/dgk78 >. Acesso em: 15 jun. 2019.

SOUZA, J. O. P. de; ALMEIDA, J. D. M. D. 2014. Modelo Digital De Elevação E Extração Automática De Drenagem: Dados, Métodos E Precisão Para Estudos Hidrológicos E Geomorfológicos. Boletim de Geografia v. 32, n. 2, p. 134.

THOMAS, H. 2017. A methodology for combining terrestrial and aerial photographs to create high resolution photogrammetric models of large-scale archaeological sites: A case study for Methone, Greece. Journal of Archaeological Science: Reports, v. 16, p. 27-33. 
THOMAS, H.; KENNEDY, M. A. 2016. A new methodology for accurate digital planning of archaeological siteswithout the aid of surveying equipment. Journal of Archaeological Science: Reports, v. 10, p. 887892.

TOMMASELLI, A. M. G. et al. 1999. Fotogrametria a curta distância. In: MENEGUETE JR, M.; ALVES, N. FCT 40 anos, Perfil Científico - Educacional. Presidente Prudente: FCT, p. 147-159.

TORRES, R. et al. 2017. Mapeando em profundidade: a integração de técnicas digitais para a pesquisa arqueológica de sítios de naufrágios históricos. VESTÍGIOS - Revista Latino-Americana de Arqueologia Histórica, Belo Horizonte, v. 11, n. 1, p. 105-134.

TORRES, R. 2017. Arqueologia Histórica na Era Digital. v. 11, p. 5-19.

VALERO, M. Á.; HUETE, N. 2016. International Congress on Archaeology, Computer Graphics, Cultural Heritage and Innovation 'Arqueológica 2.0'. La aplicación de nuevas tecnologías en la documentación arqueológica de la villa romana de noheda y su proyección turística digital. Valência: Editorial Universitat Politècnica de Valencia, p. 220-230. 